\title{
Avaliação "in vitro" do efeito da infusão de Cunila microcephala Benth sobre a atividade da enzima acetilcolinesterase e biomarcadores de estresse oxidativo em eritrócitos de agricultores
}

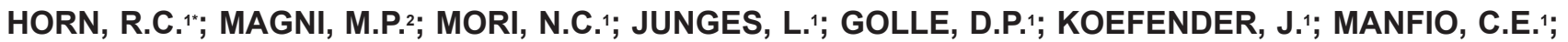
GELATTI, G.T.'; FELIPPIN, T. ${ }^{1}$

1 Universidade de Cruz Alta (UNICRUZ). Rodovia Municipal Jacob Della Méa, Km 5.6, 98.020-290. Cruz Alta RS - Brasil. 2Universidade Federal de Santa Maria (UFSM). Av. Roraima número 1000. CEP - 97105-900. Bairro: Camobi, Cidade Universitária, Santa Maria, RS, Brasil. *Autor para correspondência: robertacattaneo82@gmail.com

RESUMO: Tivemos como objetivo avaliar o efeito da infusão de Cunila microcephala Benth sobre a atividade da enzima acetilcolinesterase (AChE) e marcadores de estresse oxidativo em eritrócitos de agricultores. Foram utilizadas amostras provenientes de 16 trabalhadores rurais expostos a pesticidas agrícolas pelo período mínimo de 5 anos e um grupo controle constituído de 16 indivíduos não expostos a agrotóxicos. As hemácias dos agricultores e o grupo A foram expostos "in vitro" à solução salina $(\mathrm{NaCl} 0,9 \%)$. Os demais grupos foram expostos à infusão de poejo nas concentrações de 0; 5; 10; 25 e $50 \mathrm{~g} / \mathrm{L}$ (Grupos B; C; D e E, respectivamente). Em seguida, foram realizadas as determinações da atividade da $A C h E$ e dos níveis de substâncias reativas ao ácido tiobarbitúrico (TBARS), proteínas carboniladas (PCs) e glutationa reduzida (GSH). Os resultados mostram que a infusão de poejo $50 \mathrm{~g} / \mathrm{L}$, aumenta a atividade da enzima AChE e os níveis de GSH. Contudo, os níveis de TBARS e PCs diminuíram após o tratamento com a infusão de poejo 25 e $50 \mathrm{~g} / \mathrm{L}$. A infusão de poejo, na concentração de $50 \mathrm{~g} / \mathrm{L}$, é capaz de reverter, "in vitro" a inibição da atividade da AChE que ocorre pela exposição a pesticidas, e ainda demonstra um importante potencial antioxidante, tendo em vista que diminuiu danos lipídicos e proteicos e ainda, estimulou a produção do principal antioxidante não enzimático endógeno.

Palavras-Chave: Pesticidas, Estresse Oxidativo, Poejo.

\begin{abstract}
Effect of the Cunila microcephala Benth infusion on the activity of Acetilcolinesterase enzyme and on the biomarkers of oxidative stress in farmers erythrocytes. Evaluating the effect of infusion Cunila microcephala Benth on acetylcholinesterase activity (AChE) enzyme and on biomarkers of oxidative stress in farmers erythrocytes. We used samples from 16 rural workers exposed to pesticides for a minimum of five years, and a control group composed of 16 individuals not exposed to pesticides. The erythrocytes of farmers and from group A were exposed "in vitro" the saline solution $(\mathrm{NaCl} 0,9 \%)$. The other groups were exposed to the infusion of "poejo" at concentrations of $0 ; 5 ; 10 ; 25$ and $50 \mathrm{~g} / \mathrm{L}$ (Groups B, C, $\mathrm{D}$ and $\mathrm{E}$, respectively). Then, it was realized the analitical determinations of AChE activity and TBARS, PCs and GSH levels. The results showed that "poejo" infusion $50 \mathrm{~g} / \mathrm{L}$, increased the AChE activity and GSH levels. However, the TBARS e PCs levels decreased after the treatment with "poejo" infusion 25 e $50 \mathrm{~g} / \mathrm{L}$. The "poejo" infusion $50 \mathrm{~g} / \mathrm{L}$ is able to revert "in vitro" the inhibition of AChE activity that occurs by exposure to pesticides and also demonstrates an important antioxidant potential, given that decreased lipid and protein damage and also it stimulated the production of the main non-enzymatic antioxidant endogenous.
\end{abstract}

Keywords: Pesticides, Oxidative stress, Poejo.

\section{INTRODUÇÃO}

Os pesticidas se tornaram indispensáveis na agricultura intensiva para aumentar a produtividade. No entanto, no momento da manipulação destes produtos pode ocorrer a exposição ocupacional dos trabalhadores do meio rural. Estas exposições podem ocorrer ao contato com diferentes misturas de 
pesticidas, simultaneamente ou em série, tornandose difícil identificar o efeito de cada pesticida individualmente (Prakasam et al., 2001; Abdollahi et al., 2004). Neste contexto, o monitoramento ocupacional tem se mostrado a forma mais eficiente de prevenir e diagnosticar precocemente os episódios de intoxicações provocados por pesticidas, em particular aquelas provocadas por pesticidas inibidores da enzima acetilcolinesterase (AChE), como os organofosforados os carbamatos (Ellman et al., 1961; Silva et al., 2001). Atualmente a avaliação da atividade da enzima acetilcolinesterase no sangue é o método convencional de avaliar o grau de exposição ocupacional aos pesticidas.

Além disso, sabe-se que a exposição a estes agroquímicos estão associadas a danos em organismos não alvos, como os humanos, causando neurotoxicidade, efeitos cancerígenos e imunológicos, distúrbios reprodutivos e de desenvolvimento, que por sua vez, podem estar relacionados à ocorrência do estresse oxidativo (Murussi et al., 2014). O estresse oxidativo é um desequilíbrio entre as espécies reativas de oxigênio (EROs) produzidas e a ação do sistema antioxidante endógeno, o que favorece a oxidação de biomoléculas, gerando marcadores derivados, sobretudo, da oxidação de lipídeos, proteínas e ácido desoxirribonucléico (DNA), sendo os primeiros os de maior expressão (Rodrigues \& Almeida, 2005; Barbosa et al., 2010).

O excesso das EROs no organismo é combatido por antioxidantes produzidos pelo corpo ou adquiridos na dieta. O sistema de defesa antioxidante tem a função de inibir e/ou reduzir os danos causados pela ação deletéria destes agressores (Clarkson \& Thompson, 2000; Koury \& Donagelo, 2003). Os antioxidantes podem ser divididos em enzimáticos e não enzimáticos. Os primeiros são capazes de bloquear a iniciação da oxidação, ou seja, são as enzimas que removem as espécies reativas (ERs). Os segundos são moléculas que interagem com as espécies radicalares e são consumidas durante as reações antioxidantes (Moreira et al., 2004).

Estudos fitoquímicos realizados com a Cunila microcephala Benth, constataram a presença de substâncias fenólicas como taninos, cumarinas e flavonóides nesta planta, o que sugere uma possível ação antioxidante da mesma, visto que, a presença de um anel aromático e hidroxilas são comuns entre estes compostos, e esta estrutura é frequentemente relacionada a ação antioxidante (Angelo \& Jorge, 2007). A C. microcephala é uma erva rasteira pertencente à família Lamiaceae, conhecida popularmente como poejo (C. microcephala) e nativa da região sul do Brasil, Argentina e Uruguai. Suas folhas e flores são usadas em forma de chá, como estimulante, aromático, anti-espasmódico e no tratamento de tosse crônica e infecções respiratórias. Não são conhecidos relatos de intoxicação pelo uso desta planta (Felisbino et al., 2014).

Portanto, tendo em vista o cenário atual, onde cada vez mais busca-se a aplicação de plantas para o tratamento, prevenção e cura de doenças, bem como a ampla utilização empírica do poejo (C. microcephala), se faz importante investigar o potencial antioxidante desta planta, assim como avaliar seu possível efeito sobre a atividade da enzima AChE.

\section{MATERIAIS E MÉTODOS \\ Aspectos éticos}

Este trabalho foi aprovado pelo comitê de ética (CEP) da Universidade de Cruz Alta sob protocolo $n^{\circ}$ 0071.0.417.000-11.

\section{Seleção da Amostragem}

As amostras de sangue foram obtidas de 16 agricultores rurais, residentes na cidade de Boa Vista do Incra-RS. Os voluntários eram do sexo masculino com idade entre 18 e 59 anos e que trabalhavam no mínimo a cinco anos em lavouras de soja, trigo ou milho com exposição á pesticidas

Preparação da Infusão da C. microcephala Ainfusão é o método de preparação indicado para partes de drogas vegetais de consistência menos rígida tais como folhas, flores, inflorescências e frutos, ou que contenham substâncias ativas voláteis. Neste estudo, foram utilizadas as folhas de C. microcephala provenientes do horto da Universidade de Cruz Alta-Unicruz, Rio Grande do Sul. A preparação da infusão consistiu em verter água fervente $\left(100^{\circ} \mathrm{C}\right)$ sobre as folhas frescas da planta, em um frasco de vidro que permaneceu fechado e em repouso pelo tempo de 10 minutos (Brasil, 2011). A partir da infusão de poejo a $50 \mathrm{~g} / \mathrm{L}$ foram preparadas as demais concentrações da infusão utilizadas neste estudo: 5;10 e $25 \mathrm{~g} / \mathrm{L}$.

\section{Caracterização da Infusão da $C$. microcephala}

As determinações de Polifenóis Totais, Flavonoides Totais e Taninos Condensados foram realizadas utilizando $200 \mathrm{~mL}$ da infusão de $C$. microcephala na concentração de 50g/L liofilizada.

\section{Determinação dos Polifenóis Totais}

A determinação dos Polifenóis Totais foi realizada de acordo com o método descrito por Chandra \& Mejia (2004), com pequenas modificações. A infusão de $50 \mathrm{~g} / \mathrm{L}$ de poejo liofilizada, foi diluída com água destilada a uma concentração

Rev. Bras. PI. Med., Campinas, v.18, n.1, supl. I, p.341-348, 2016. 
de $0,15 \mathrm{mg} / \mathrm{mL}$. A essa solução foi acrescido carbonato de sódio a $20 \%$ e após 5 minutos foi adicionado o reagente Folin-Ciocalteau 2N. Esta mistura reacional foi incubada por 10 minutos e as leituras realizadas em espectrofotômetro visível a $730 \mathrm{~nm}$. Os testes foram realizados em triplicata e para o cálculo do doseamento de polifenóis totais foi utilizada uma curva padrão de ácido gálico. Os resultados foram expressos por $\mathrm{mg}$ acido gálico/g massa seca.

\section{Determinação dos Flavonoides Totais}

O teor de Flavonoides Totais foi determinado de acordo com o método descrito por Woisky \& Salatino (1998), com pequenas modificações. A infusão de $50 \mathrm{~g} / \mathrm{L}$ de poejo liofilizada, foi diluída com metanol a uma concentração de $1 \mathrm{mg} / \mathrm{mL}$. A essa solução foi acrescido cloreto de alumínio a $2 \%$ e metanol. Essa mistura ficou em capela de exaustão parada, por 30 minutos, à temperatura ambiente. As leituras foram realizadas em espectrofotômetro visível a $420 \mathrm{~nm}$. Os testes foram realizados em triplicata e para o cálculo do doseamento de flavonoides foi utilizada uma curva padrão de quercetina. Os resultados foram expressos por $\mathrm{mg}$ quercetina/g massa seca.

\section{Determinação dos Taninos Condensados}

A determinação de Taninos Condensados foi realizada utilizando o método descrito por Morrison et al. (1995), com pequenas modificações. A infusão de $50 \mathrm{~g} / \mathrm{L}$ de poejo liofilizada, foi diluída com metanol a uma concentração de $25 \mathrm{mg} / \mathrm{mL}$. A essa solução foi acrescido metanol, solução de vanilina $0,01 \mathrm{~g} / \mathrm{mL}$ e ácido cloridrico $0,08 \mathrm{M}$. A mistura foi aquecida à $60^{\circ} \mathrm{C}$ por 10 minutos. As leituras foram realizadas em espectrofotômetro visível a $420 \mathrm{~nm}$. Os testes foram realizados em triplicata e para o cálculo do doseamento de taninos condensados foi utilizada uma curva padrão de catequina. Os resultados foram expressos por mg catequina/g massa seca.

\section{Coleta e Tratamento das Amostras}

Foram utilizadas amostras de agricultores rurais, sexo masculino, com idade entre 18 e 59 anos e que trabalhavam no mínimo a três anos no ramo da agricultura (critérios de inclusão). Todos os voluntários responderam um questionário sobre saúde ocupacional com perguntas estruturadas visando utilizar estes dados para selecionar os participantes da pesquisa respeitando os critérios de exclusão, tais como: não ser fumante, não ser etilista e não possuir doença crônica.

O grupo controle foi composto por amostras provenientes de 16 indivíduos saudáveis e nunca tiveram contato direto com agroquímicos.
As coletas de sangue dos participantes foram realizadas através do uso de vacutainers contendo ácido etilenodiamino tetra-acético (EDTA). As amostras foram centrifugadas a $3000 \mathrm{rpm}$ durante 10 min e os plasmas foram removidos. Logo, os eritrócitos foram lavados e diluídos com solução salina ( $\mathrm{NaCl} 0,9 \%)$ até atingirem um hematócrito de $5 \%$ de acordo com a técnica determinada por Catalgol et al. (2007) adaptada por Horn et al. (2015). Posteriormente, foi realizado o tratamento dos eritrócitos com a infusão do Poejo (C. microcephala), onde foi adotado um protocolo experimental contendo os cinco grupos a seguir:

-Grupo Controle: hemácias de indivíduos não expostos a agrotóxicos tratadas com solução salina $(\mathrm{NaCl} 0,9 \%)$;

- Grupo A: hemácias dos agricultores tratadas com solução salina $(\mathrm{NaCl} 0,9 \%)$;

- Grupo B: hemácias dos agricultores tratados com a infusão de $5 \mathrm{~g} / \mathrm{L}$ de poejo ( $C$. microcephala);

- Grupo C: hemácias dos agricultores tratados com a infusão de $10 \mathrm{~g} / \mathrm{L}$ de poejo (C. microcephala);

-Grupo D: hemácias dos agricultores tratados com a infusão de $25 \mathrm{~g} / \mathrm{L}$ de poejo (C. microcephala);

- Grupo E: hemácias dos agricultores tratados com a infusão de $50 \mathrm{~g} / \mathrm{L}$ de poejo (C. microcephala).

Todas as amostras foram incubadas por 1 hora em banho-maria a $37^{\circ} \mathrm{C}$, hemolisados no vórtex e centrifugadas. O produto final após a centrifugação foi armazenado a $-20^{\circ} \mathrm{C}$ para a realização das determinações analíticas.

\section{Determinações analíticas}

Análise da Atividade da Enzima Acetilcolinesterase (AChE)

A análise da atividade da enzima AChE foi realizada através da metodologia descrita por Ellman et al. (1961), sendo determinada em espectrofotômetro em leitura de $412 \mathrm{~nm}$. Os resultados foram expressos por $\mu \mathrm{mol}$ substrato hidrolisado/min/g Hb.

\section{Determinação dos níveis de Peroxidação Lipídica (TBARS)}

Determinou-se a peroxidação lipídica de acordo com o método de formação de espécies reativas ao ácido tiobarbitúrico (TBARS), conforme protocolos de Stock \& Dormandy (1971). O sobrenadante foi adicionado à mistura reacional contendo ácido tricloroacético (TCA) a $28 \%(\mathrm{v} / \mathrm{v})$ e ácido tiobarbitúrico (TBA) $(0,1 \mathrm{~mol} / \mathrm{L})$ seguido de aquecimento a $95^{\circ} \mathrm{C}$. As leituras foram realizadas em espectrofotômetro visível a $532 \mathrm{~nm}$, comprimento

Rev. Bras. PI. Med., Campinas, v.18, n.1, supl. I, p.341-348, 2016. 
no qual o produto formado, malondialdeído (MDA), pode ser medido. Os resultados foram expressos porl nmol/g Hb.

\section{Determinação dos Níveis de Proteínas Carboniladas}

As análises foram realizadas a partir da técnica descrita por Levine (1990) adaptada para eritrócitos, em que previamente o sobrenadante é diluído com Hepes, e com posterior determinação das proteínas carboniladas, utilizando TCA a $10 \%(\mathrm{v} / \mathrm{v})$, ácido clorídrico 2N; 2,4-Dinitrofenilhidrazina (DNPH) a $10 \mathrm{mM}$ e dodecil sulfato de sódio (SDS) $3 \%(\mathrm{~m} / \mathrm{v})$. As leituras foram realizadas em espectrofotômetro visível, em $370 \mathrm{~nm}$. Os resultados foram expressos por nmol de carbonil/mg de proteína. As Proteínas Totais foram determinadas nos eritrócitos diluídos com hepes a partir do protocolo do kit comercial da marca Labtest ${ }^{\circledR}$.

\section{Determinação dos Níveis de Glutationa Reduzida (GSH) \\ Determinada a partir da técnica descrita por} de Ellman (1959) adaptada para eritrócitos, em que se utiliza tampão fosfato de potássio (TFK) a $1 \mathrm{M} \mathrm{em}$ pH 7,4 e ácido 5,5'-ditiobis-(2-nitrobenzóico) (DTNB) como reagente de cor. As leituras foram realizadas em espectrofotômetro visível, em $412 \mathrm{~nm}$. Os resultados foram expressos por $\mu \mathrm{mol} \mathrm{GSH} / \mathrm{mL}$ de sobrenadante.

\section{Determinação da Hemoglobina}

A hemoglobina foi determinada com a utilização de kits comerciais da marca Labtest ${ }^{\circledast}$.

\section{Métodos Estatísticos}

As determinações analíticas realizadas em duplicata e os resultados foram expressos por média \pm EP (erro padrão). Os dados obtidos de todos os grupos estudados, para um mesmo parâmetro, foram submetidos à Análise de Variância (ANOVA) de uma via seguido do teste de TukeyKramer, considerando as médias significativamente diferentes com um $P<0,05$. Utilizando o programa estatístico Graph Pad Prism ${ }^{\circledR}$ 5.0.

\section{RESULTADOS}

As características dos voluntários participantes deste estudo estão apresentadas na Tabela 1. Tanto os indivíduos saudáveis quanto os agricultores eram homens (100\%). A idade média do grupo controle foi de $40 \pm 5$ anos, enquanto que dos trabalhadores rurais foi de $43 \pm 9$ anos. $O$ tempo médio de exposição dos trabalhadores rurais aos agrotóxicos foi de $16,6 \pm 10.1$ anos. Apenas 36\% destes utilizavam equipamentos de proteção individual (EPIs) e a última exposição média aos agroquímicos foi a $46,5 \pm 8,6$ dias.

A Tabela 2 mostra as quantidades de polifenóis totais $(70,96 \pm 1,02)$, flavonoides totais $(34,50 \pm 0,14)$ e taninos condensados $(6,22 \pm 1,01)$ presentes na infusão-mãe $(50 \mathrm{~g} / \mathrm{L})$ testada neste estudo.

Os níveis da atividade da enzima AChE nos eritrócitos dos trabalhadores rurais avaliados neste estudo, aumentaram significativamente quando expostos à concentração de $50 \mathrm{~g} / \mathrm{L}$ de "poejo" ( $C$. microcephala) (Figura 1).

Com relação aos níveis dos TBARS avaliados neste estudo, observou-se uma redução significativa deste parâmetro nos grupos $B(5 \mathrm{~g} / \mathrm{L})$, $D(25 \mathrm{~g} / \mathrm{L})$ e grupo $E(50 \mathrm{~g} / \mathrm{L})$. (Figura 2). Ainda, nos grupos D (25g/L) e E (50g/L) também foi observada uma diminuição da carbonilação proteica (Figura 3). $\mathrm{Na}$ Figura 4, está demonstram que os níveis deste marcador estavam aumentados no grupo $E(50 \mathrm{~g} / \mathrm{L})$.

\section{DISCUSSÃO}

Os antioxidantes naturais, tais como os compostos fenólicos totais, desempenham um importante papel na neutralização de espécies reativas, quelando o oxigênio triplete e singlete ou decompondo peróxidos (Leopoldini et al., 2011; Oroian \& Escriche, 2015). A presença destes fitoquímicos antioxidantes, bem como a identificação de flavonóides e taninos condensados na infusão de poejo testada neste estudo indica que esta planta possui efeito benéfico sobre os parâmetros de estresse oxidativo, já que Stevenson \& Hurst (2007) sugerem em sua revisão que os polifenóis são

TABELA 1. Perfil dos participantes do estudo

\begin{tabular}{|c|c|c|}
\hline & Grupo Controle & Agricultores \\
\hline Sexo Masculino (\%) & 100 & 100 \\
\hline Idade (Anos) & $40 \pm 5$ & $43 \pm 9$ \\
\hline Tempo de Exposição (Anos) & - & $16,6 \pm 10.1$ \\
\hline Utilização de Equipamentos de proteção individual (\%) & - & 36 \\
\hline Última aplicação (Dias) & - & $46,5 \pm 8,6$ \\
\hline
\end{tabular}

Rev. Bras. PI. Med., Campinas, v.18, n.1, supl. I, p.341-348, 2016. 
TABELA 2. Quantificação de polifenóis totais, flavonoides totais e taninos condensados presentes na infusão de C. microcephala $50 \mathrm{~g} / \mathrm{L}$. Os resultados foram expressos por média \pm desvio padrão.

\begin{tabular}{l|c|c|c}
\hline Amostra & $\begin{array}{c}\text { Polifenóis Totais } \\
\text { mg ácido gálico/g } \\
\text { massa seca }\end{array}$ & $\begin{array}{c}\text { Flavonoides Totais } \\
\text { mg quercetina/g } \\
\text { massa seca }\end{array}$ & $\begin{array}{c}\text { Taninos Condensados } \\
\text { mg catequina/g } \\
\text { massa seca }\end{array}$ \\
\hline Infusão de C. microcephala 50g/L & $70,96 \pm 1,02$ & $34,50 \pm 0,14$ & $6,22 \pm 1,01$ \\
\hline
\end{tabular}

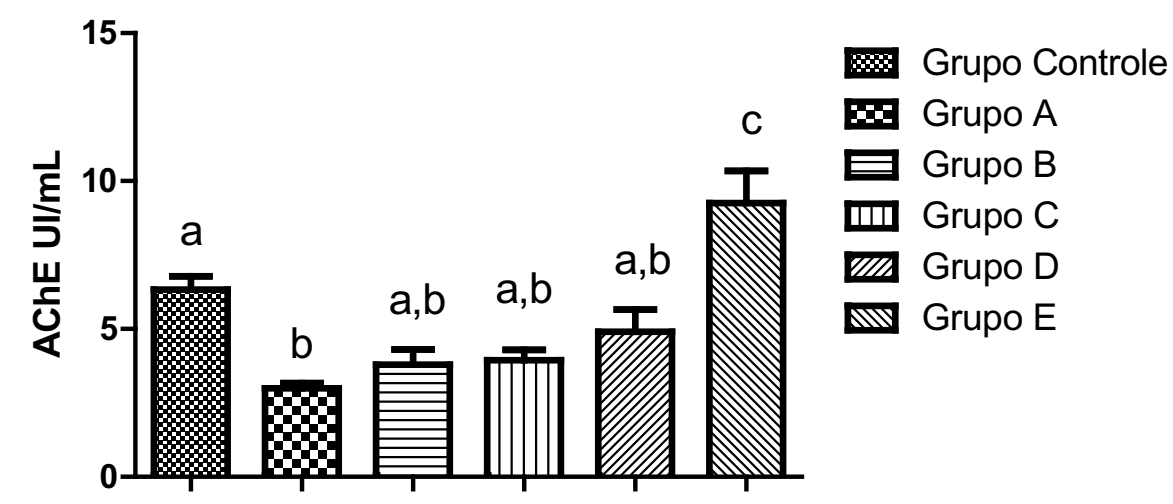

FIGURA 1. Atividade da enzima $A C h E(U I / m L)$ nos eritrócitos de trabalhadores rurais tratados com a infusão do poejo em diferentes concentrações. Letras distintas representam resultados significativamente diferentes $(p<0,05)$.

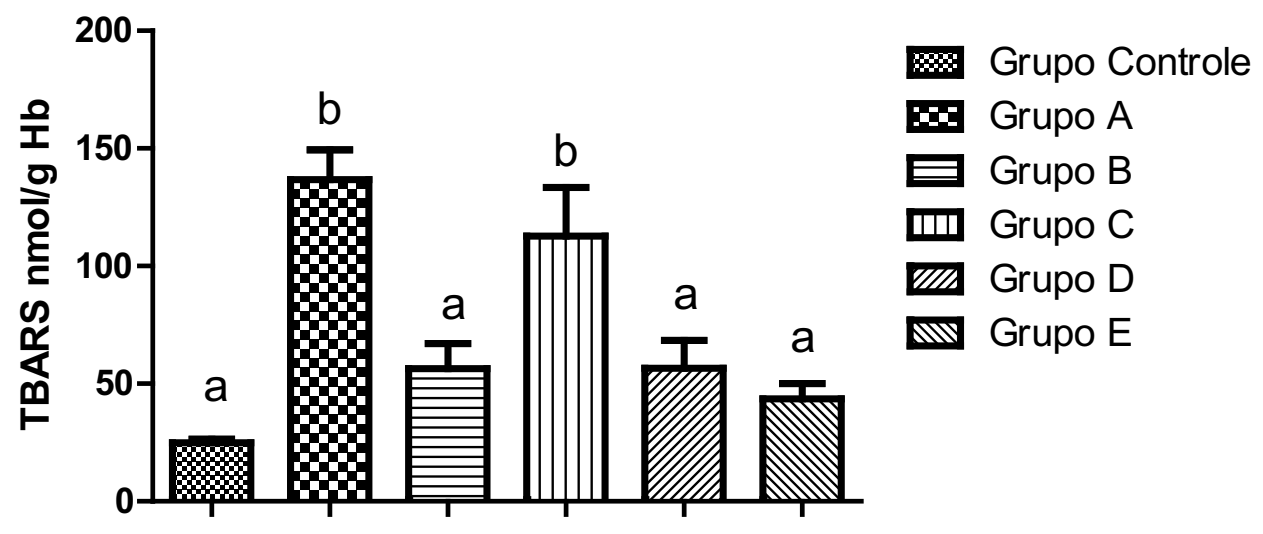

FIGURA 2. Níveis de TBARS ( $\mathrm{nmol} / \mathrm{g} \mathrm{Hb}$ ) nos eritrócitos de trabalhadores rurais tratados com a infusão de poejo em diferentes concentrações. Letras distintas representam resultados significativamente diferentes $(p<0,05)$.

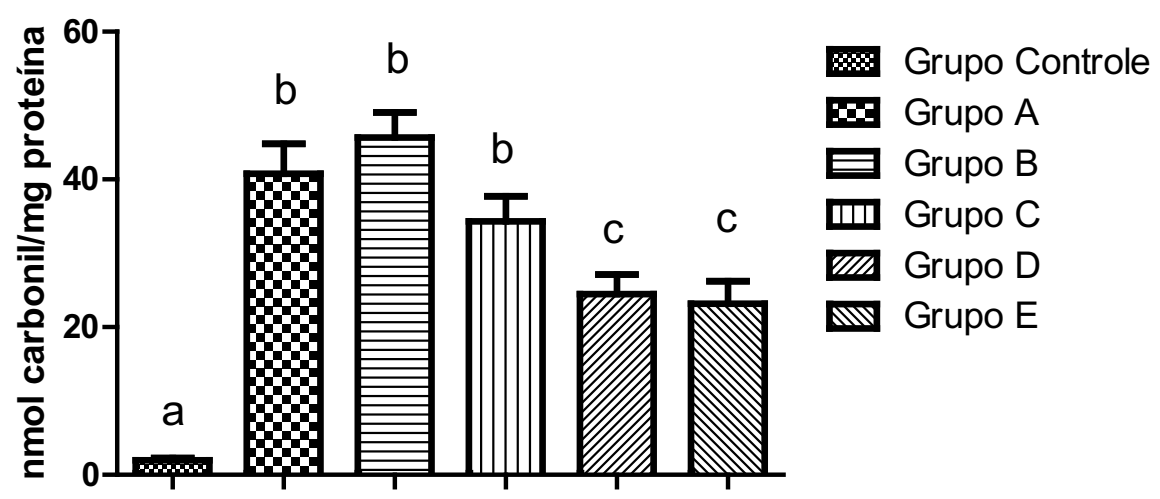

FIGURA 3. Níveis de PCs (nmol carbonil/mg prot totais) nos eritrócitos de trabalhadores rurais tratados com a infusão de poejo em diferentes concentrações. Letras distintas representam resultados significativamente diferentes $(p<0,05)$. 


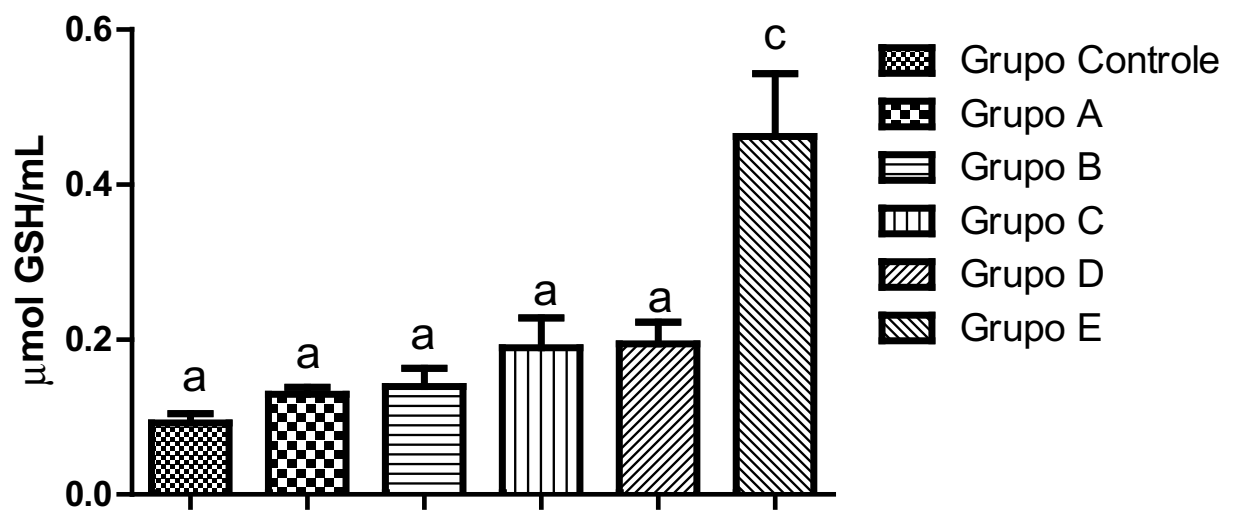

FIGURA 4. Níveis de GSH ( $\mu \mathrm{mol} \mathrm{GSH} / \mathrm{mL}$ ) nos eritrócitos de trabalhadores rurais tratados com a infusão de poejo em diferentes concentrações. Letras distintas representam resultados significativamente diferentes $(p<0,05)$.

capazes de fornecer proteção significativa contra o estresse oxidativo "in vitro" em concentrações muito menores do que seria necessário para um antioxidante químico (Oroian \& Escriche, 2015). Estes resultados corroboram com os achados de Felisbino et al. (2014) que também revelaram a presença de compostos fenólicos no extrato da folha de C. microcephala.

A inibição da enzima acetilcolinesterase (AChE) constitui um parâmetro fundamental para caracterização da exposição ambiental humana à agroquímicos, tendo em vista que as principais classes de pesticidas utilizadas pelos agricultores promovem alterações sobre o sistema nervoso dos mesmos (Lionetto et al., 2013). Considerando a elevação da atividade desta enzima no grupo $E$, é possível afirmar que a concentração de $50 \mathrm{~g} / \mathrm{L}$ da infusão do poejo mostrou um efeito benéfico frente a inibição da AChE promovida pelos agroquímicos (Figura 1 ). A reativação da AChE é possível, desde que o grupo hidroxila da serina presente nesta enzima e, fosforilado pelos agroquímicos encontre um nucleófilo, geralmente uma oxima pirimidíca, cujo grupo hidroxila é capaz de remover o grupo fosfato, reativando a enzima (Katz et al., 2015).

No que diz respeito aos danos oxidativos, a exposição aos xenobióticos pode levar à oxidação de macromoléculas, tais como: lipídeos, proteínas e DNA. A lipoperoxidação é definida como uma cascata de eventos bioquímicos resultante da ação das EROs sobre os lipídeos constituintes das membranas celulares (Lima \& Abdalla, 2001). Simoniello et al. (2009) demonstram em seus estudos uma elevação dos níveis de TBARS de agricultores expostos à pesticidas, corroborando com o resultado do nosso estudo (Figura 2). A Figura 2, demonstra que a infusão de poejo nas concentrações de $5 ; 25 ; 50 \mathrm{~g} / \mathrm{L}$ foi capaz de diminuir os lipídios peroxidados nos eritrócitos dos trabalhadores rurais. Este fato é de extrema relevância, tendo em vista que a ocorrência deste evento nos trabalhadores rurais aumenta o risco do desenvolvimento de doenças, como: doenças neurodegenerativas, respiratórias e câncer (Oliveira et al., 2013; Choi et al., 2014). Além disso, os endoperóxidos provenientes da peroxidação lipídica sofrem fragmentação produzindo compostos carbonílicos que podem ser ainda mais destrutivos do que as EROs, tendo efeito prejudicial de longo prazo em macromoléculas como proteínas e DNA (NegreSalvayre et al., 2010). O fato do grupo C (10g/L) não ter apresentado o mesmo comportamento dos demais tratados com a infusão do poejo pode remeter a um erro metodológico, visto que, tanto concentrações mais altas quanto mais baixas da infusão testada demonstraram efeito benéfico sobre a peroxidação lipídica.

Outro parâmetro oxidativo frequentemente elevado em agricultores expostos a pesticidas agrícolas são as PCs. De acordo com Sledzinski et al. (2008) e Murussi et al. (2014), a formação de compostos carbonílicos é irreversível, contudo estes podem ser removidos por mecanismos proteoliticos (Costa et al., 2007). Assim, considerando que nesta pesquisa ocorreu redução dos níveis de PCs nos grupos $\mathrm{D}$ e E, em pouco tempo de tratamento com a infusão de poejo, sugere-se que a planta estudada nas concentrações de 25 e $50 \mathrm{~g} / \mathrm{L}$, mostraramse capaz de estimular a remoção das proteinas carboniladas.

Em contrapartida aos parâmetros oxidativos, a GSH é considerada um antioxidante multifuncional, que está presente no plasma e nas hemácias e possui grande importância pelo fato de possuir papel central na biotransformação e eliminação de xenobióticos e na defesa das células contra o estresse oxidativo (Barbosa et al., 2010). De acordo com Figura 4, os níveis 
deste marcador foram elevados no grupo $\mathrm{E}$ $(50 \mathrm{~g} / \mathrm{L})$ após o tratamento com a infusão de poejo, o que provavelmente pode ter ocorrido devido a uma elevação na atividade da enzima glutationa reduzida (GR), tendo em vista que esta é responsável pela conversão da glutationa oxidada (GSSG) em glutationa reduzida (Aquilano et al., 2014).

Portanto, através dos testes realizados neste estudo verifica-se que a infusão de poejo na concentração $50 \mathrm{~g} / \mathrm{L}$ pode ser capaz de reverter a inibição da enzima AChE, bem como beneficiar a ação do sistema antioxidante dos agricultores expostos a pesticidas agrícolas. Assim, investigações futuras acerca desta planta tornamse fundamentais, visto que a mesma pode vir a se apresentar como uma alternativa terapêutica para agricultores intoxicados por agroquímicos.

\section{REFERÊNCIAS}

ABDOLLAHI, M.; et al. Pesticides and oxidative stress: a review. Revista Medical Science Monitor, v.10, n.6, p.141-147, 2004.

ANGELO, P.M; JORGE, N. Compostos fenólicos em alimentos - uma breve revisão. Revista Instituto Adolfo Lutz, v.66, n.1, p.1-9, 2007.

AQUILANO, K.; et al. Glutathione: new roles in redox signaling for an old antioxidant. Frontiers in Pharmacology, v.5, n.196, p.1-12, 2014.

BARBOSA, K.B.; et al. Estresse oxidativo: conceito, implicações e fatores modulatórios. Revista de Nutrição, v.23, n.4, p.629-643, 2010.

BRASIL. Agência Nacional de Vigilância Sanitária. Formulário de Fitoterápicos da Farmacopeia Brasileira. 1.ed. Brasília: Anvisa, 2011. 126p.

CATALGOL, B.K.; et al. Effect of trichlorfon on malondialdehyde and antioxidant system in human erythrocytes. Toxicology In Vitro, v.21, n.8, p.15381544, 2007.

CHANDRA, S.; MEJIA, E.G. Polyphenolic compounds, antioxidant capacity and quinone reductase activity of na aqueous extract of Ardisia compressa in comparison to Mate (Ilex paraguariensis) and Green (Camellia sinensis) Teas. Journal of Agricultural and Food Chemistry, v.52, n.1, p.3583-3589, 2004.

$\mathrm{CHOI}, \mathrm{S}$; ; et al. Are sensory TRP channels biological alarms for lipid peroxidation? International Journal of Molecular Sciences, v.15, n.9, p.16430-16457, 2014.

CLARKSON, P.M.; THOMPSON, H.S. Antioxidants: what role do they play in physical activity and health? The American Journal of Clinical Nutrition, v.72, n.2, p.637-646, 2000.

COSTA, V.; et al. Protein oxidation, repair mechanisms and proteolysis in saccharomyces cerevisiae. IUBMB Life, v.59, n.4-5, p.293-298, 2007.

ELLMAN, G.L. Tissue sulfhydryl group. Archives of Biochemistry and Biophysics, v.7, n.1, p.70-82, 1959.

ELLMAN, G.L.; et al. A new and rapid colorimetric determination of acetylcholin-esterase activity. Biochemical Pharmacology, v.7, n.7, p.88-95, 1961.

FELISBINO, A.S.; et al. Preliminary investigation on phytochemical composition and biological activity of Cunila microcephala Benth. Journal of Medicinal Plants Research, v.8, n.21, p.780-787, 2014.

HORN, R.C.; et al. Antioxidant effect of Physalis peruviana fruit aqueous extract. Journal of Agricultural Science, v.7, n.12, p.137-143, 2015.

KATZ, F.S.; et al. Discovery of new classes of compounds that reactivate acetylcholinesterase inhibited by organophosphates. ChemBioChem, v.16, n.15, p.2205-2215, 2015.

KOURY, J.C.; DONAGELO, C.M. Zinco, estresse oxidativo e atividade física. Revista de Nutrição, v.16, n.4, p.433-441, 2003.

LEOPOLDINI, M.; et al. The molecular basis of working mechanism of natural polyphenolic antioxidants. Food Chemistry, v.125, n.2, p.288-306, 2011.

LEVINE, R.L. Determination of carbonil in oxidatively modified proteins. Methods in Enzymology, v.186, p.464-468, 1990.

LIMA, E.S.; ABDALLA, D.S.P. Peroxidação Lipídica: mecanismos e avaliação em amostras biológicas. Revista Brasileira de Ciências Farmacêuticas, v.37, n.3, p.293-303, 2001.

LIONETTO, M.G.; et al. Acetylcholinesterase as a biomarker in environmental and occupational medicine: new insights and future perspectives. BioMed Research International, v.2013, p.1-8, 2013.

MOREIRA, A.V.; et al. Influência dos compostos fenólicos de especiarias sobre a lipoperoxidação e o perfil lipídico de tecidos de ratos. Revista de Nutrição, v.17, n.4, p.411-424, 2004.

MORRISON, I.M.; et al. Determination of lignin and tannin contents of Cowpea seed coats. Annals of Botany, v.76, n.3, p.287-290, 1995.

MURUSSI, C.; et al. Changes in oxidative markers, endogenus antioxidants and activity of the enzyme acetylcholinesterase in farmers exposed to agricultural pesticides - a pilot study. Ciência Rural, v.44, n.7, p.1186-1193, 2014.

NEGRE-SALVAYRE, A.; et al. Pathological aspects of lipid peroxidation. Free Radical Research, v.44, n.10, p.1125-1171, 2010.

OLIVEIRA, Q.C.B.S.; et al. Níveis indesejáveis de colesterol total no organismo humano e a ocorrência de estresse oxidativo. Biomotriz, v.7, n.2, p.95-107, 2013.

OROIAN, M.; ESCRICHE, I. Antioxidants: chacterization, natural sources, extraction and analysis. Food Research International, v.74, p.10-36, 2015.

PRAKASAM, A.S; et al. Plasma and RBCs antioxidant status in occupational male pesticide sprayers. Clinica Chimica Acta, v.310, n.2, p.107-112, 2001.

RODRIGUES, B.N.; ALMEIDA, F.S. Guia de Herbicidas. 5.ed. Londrina: Lapar, 2005. 591p.

SILVA, J.J.O.; et al. Influência de fatores socioeconômicos na contaminação por agrotóxicos, Brasil. Revista de Saúde Pública, v.35, n.2, p.130-135, 2001.

SIMONIELLO, M.F.; et al. Biochemical evaluation on rural workers exposed to pesticides. Medicina, v.70, n.6, p.489-498, 2009.

SLEDZINSKI, T.; et al. Decrease in serum protein

Rev. Bras. PI. Med., Campinas, v.18, n.1, supl. I, p.341-348, 2016. 
carbonyl groups concentration and maintained hyperhomocysteinemia in patients Undergoing Bariatric Surgery. Obesity Surgery, v.19, n.3, p.321-326, 2008. STEVENSON, D.E.; HURST, R.D. Polyphenolic phytochemicals - Just antioxidants ormuch more? Cellular \& Molecular Life Sciences, v.64, n.22, p.2900-2916, 2007.
STOCK, J.; DORMANDY, T.L. The autoxidation of human red cell lipids induced by hydrogen peroxide. British Journal of Haematology, v.20, n.1, p.95-111, 1971. WOISKY, R.G.; SALATINO, A. Analysis of própolis: some parameters and procedures for chemical quality control. Journal of Apicultural Research, v.37. n.2, p.99-105, 1998.

Rev. Bras. PI. Med., Campinas, v.18, n.1, supl. I, p.341-348, 2016. 